\title{
Genome variations account for different response to three mineral elements between Medicago truncatula ecotypes Jemalong A17 and R108
}

\author{
Tian-Zuo Wang ${ }^{1}$, Qiu-Ying Tian' ${ }^{1}$ Bao-Lan Wang ${ }^{1}$, Min-Gui Zhao ${ }^{1}$ and Wen-Hao Zhang ${ }^{1,2^{*}}$
}

\begin{abstract}
Background: Resequencing can be used to identify genome variations underpinning many morphological and physiological phenotypes. Legume model plant Medicago truncatula ecotypes Jemalong A17 (J. A17) and R108 differ in their responses to mineral toxicity of aluminum and sodium, and mineral deficiency of iron in growth medium. The difference may result from their genome variations, but no experimental evidence supports this hypothesis.
\end{abstract}

Results: A total of 12,750 structure variations, 135,045 short insertions/deletions and 764,154 single nucleotide polymorphisms were identified by resequencing the genome of R108. The suppressed expression of MtAACT that encodes a putative aluminum-induced citrate efflux transporter by deletion of partial sequence of the second intron may account for the less aluminum-induced citrate exudation and greater accumulation of aluminum in roots of R108 than in roots of J. A17, thus rendering R108 more sensitive to aluminum toxicity. The higher expression-level of MtZpt2-1 encoding a TFIIIA-related transcription factor in J. A17 than R108 under conditions of salt stress can be explained by the greater number of stress-responsive elements in its promoter sequence, thus conferring J. A17 more tolerant to salt stress than R108 plants by activating the expression of downstream stress-responsive genes. YSLs (Yellow Stripe-Likes) are involved in long-distance transport of iron in plants. We found that an YSL gene was deleted in the genome of R108 plants, thus rendering R108 less tolerance to iron deficiency than J. A17 plants.

Conclusions: The deletion or change in several genes may account for the different responses of $M$. truncatula ecotypes J. A17 and R108 to mineral toxicity of aluminum and sodium as well as iron deficiency. Uncovering genome variations by resequencing is an effective method to identify different traits between species/ecotypes that are genetically related. These findings demonstrate that analyses of genome variations by resequencing can shed important light on differences in responses of $M$. truncatula ecotypes to abiotic stress in general and mineral stress in particular.

Keywords: Resequencing, Medicago truncatula, Aluminum toxicity, Aluminum- activated citrate transporter, Salt stress, MtZpt2-1, Iron deficiency, Yellow Stripe-Likes

\section{Background}

Legume is the second most important crop family in the world, and is one of primary sources for the consumption of human and animals [1,2]. Acquisition of nutrients from soil is a prerequisite for plant growth and development. Plants are frequently exposed to adverse

\footnotetext{
* Correspondence: whzhang@ibcas.ac.cn

${ }^{1}$ State Key Laboratory of Vegetation and Environmental Change, Institute of Botany, the Chinese Academy of Sciences, Beijing, P. R. China

${ }^{2}$ Research Network of Global Change Biology, Beijing Institutes of Life

Science, the Chinese Academy of Sciences, Beijing, P. R. China
}

mineral stress in soils, including aluminum toxicity in acid soil, salt stress in saline soil and iron deficiency in alkaline soil. Plants have evolved numerous mechanims to adapt to these stressed environments [3-5]. Understanding of the molecular mechanims by which plants respond and adapt to the mineral toxicity and deficiency is a major challenge in modern plant biology.

As a model legume species, Medicago truncatula Gaertn has been widely used to study functional genomics because of its small diploid genome, self-fertility, short generation cycle and easy transformation [6]. There are a 
number of ecotypes of $M$. truncatula with large genetic variations [7]. Of the ecotypes, $M$. truncatula ecotype Jemalong A17 (J. A17) has been used for the wholegenome sequencing and physiological studies [8-10], while ecotype R108 is often used for gene transformation because of its superior in vitro regeneration [11]. M. truncatula ecotype R108 differs from its counterpart J. A17 in traits associated with development, and biotic/ abiotic responses. For example, treatments of J. A17 with methyl jasmonate and ethylene induce resistance to fungal pathogen Macrophomina phaseolina, while these treatments fail to induce resistance in R108 to the fungal pathogen [12]. In addition, rhizobial-induced expression of chitinase gene between the two ecotypes is also different [13]. The two ecotypes exhibit different tolerance to salt stress, such that ecotype J. A17 is more tolerant to salt stress than R108. Further studies reveal that a TFIIIA-related transcription factor gene, MtZpt2-1 shows different expression in the two ecotypes, and that overexpression of $M t Z p t 2-1$ in roots confers enhanced tolerance to salt stress $[14,15]$. Our previous work revealed that the two ecotypes also differed in their tolerance to deficiency in mineral nutrients. For example, ecotype J. R108 was more sensitive to iron deficiency than ecotype J. A17 [16]. Despite the morphological and physiological differences between the two ecotypes, few studies have investigated the molecular mechanisms underlying the differences due to lack of information on the genome of R108.

DNA sequences contain all the genetic information, and genome variations such as structure variations (SVs), short insertions/deletions (indels) and single nucleotide polymorphisms (SNP) can explain many variations in morphological, physiological, and ecological traits [17-21]. Resequencing technology provides a powerful tool to study these variations among species/ecotypes that are closely related genetically. For instance, Thellungiella salsuginea exhibits exceptionally high resistance to cold, drought, and oxidative stresses as well as salinity [22-24]. The number of members in gene families with known functions associated with responses to abiotic stresses in T. salsuginea is greater than in Arabidopsis thaliana, including those gene families of RAV, NF-X1, GRAS, HSF, $H K T, C I P K$ and CDPK [25]. Furthermore, it has been reported that maize inbred-line Mo17 exhibits eminent heterosis due to its deletion of eighteen genes [19]. The two widely used $M$. truncatula ecotypes Jemalong A17 (J. A17) and R108 have been reported to differ in their tolerance to salt stress $[14,15]$ and iron deficiency [16]. To test whether the genome variations between J. A17 and R108 may account for the differences in their responses to mineral toxicity of aluminum and sodium and mineral deficiency of iron in growth medium, genome variations of $M$. truncatula ecotype R108 were analyzed by mapping the reads obtained from resequencing of R108 to the reference genome of ecotype J. A17.

\section{Results}

Response of J. A17 and R108 to $\mathrm{Al}^{3+}$ and $\mathrm{Na}^{+}$toxicity, and Fe deficiency

To examine the effect of $\mathrm{Al}^{3+}$ on root elongation of the two ecotypes, the relative root elongation was determined. As shown in Figure 1a, root elongation was inhibited upon exposure of the two ecotypes to solution containing $\mathrm{Al}^{3+}$, and the $\mathrm{Al}^{3+}$-induced inhibition of root elongation in R108 was greater than in J. A17. Moreover, Al contents in R108 roots were higher than in J. A17 roots (Figure 1b), implying that an exclusion mechanism may operate in ecotype J. A17 plants. Exudation of organic anions including malate and citrate to complex toxic $\mathrm{Al}^{3+}$ in the rhizosphere is an important mechanism to tolerate $\mathrm{Al}[3,26,27]$. Therefore, we monitored exudate of malate and citrate from roots of the two ecotypes in response to $\mathrm{Al}^{3+}$ treatment. There was an increase in citrate exudation from roots of J. A17 and R108 plants by exposure to $\mathrm{Al}^{3+}$, and the $\mathrm{Al}^{3+}$-induced citrate exudation from roots of $\mathrm{J}$. A17 was greater than that of R108 plants (Figure 1c). In contrast to citrate, no significant increases in malate exudation from roots of the two ecotypes by exposure to $\mathrm{Al}^{3+}$ were detected (data not shown). These results suggest that higher exudation of citrate may underpin the greater tolerance of J. A17 to Al than R108 plants. de Lorenzo et al. found that R108 is more sensitive to salt stress than J. A17 plants as evidenced by less suppression of root growth in J. A17 plants than in R108 plants [14]. In addition to root growth, $\mathrm{Na}^{+} / \mathrm{K}^{+}$ratio is an important indicator for tolerance of plants to salt stress. Excessive accumulation of toxic $\mathrm{Na}^{+}$in plant cells, particularly in the cytosol, disrupts $\mathrm{K}^{+}$homeostasis, leading to dysfunction of plant cells, thus plants displaying high tolerance to salt stress often minimize $\mathrm{Na}^{+}$uptake and/or maximize $\mathrm{K}^{+}$acquisition to maintain a low $\mathrm{Na}^{+} / \mathrm{K}^{+}$ratio [28]. Therefore, we compared the effect of salt stress on $\mathrm{Na}^{+}$and $\mathrm{K}^{+}$concentrations in the two ecotypes. No differences in both $\mathrm{Na}^{+}$and $\mathrm{K}^{+}$concentrations in shoots of the two ecotypes were found when they were grown in the control medium (Figure 2a and $b$ ). When they were exposed to solution containing $\mathrm{NaCl}$, an enhanced accumulation of $\mathrm{Na}^{+}$in both ecotypes was observed (Figure 2a). However, exposure to salt stress led to reductions in $\mathrm{K}^{+}$concentrations in shoots of both ecotypes, and the salt stress-induced reduction in $\mathrm{K}^{+}$ concentration was greater in R108 than in J. A17 plants (Figure 2b). This led to an increase in $\mathrm{Na}^{+} / \mathrm{K}^{+}$ratio in both ecotypes, and the increase was significantly less in J. A17 plants than in R108 plants (Figure 2c).

Our previous work showed that the ecotype J. A17 was more tolerant to Fe deficiency than R108 by efficiently mobilizing Fe in the rhizosphere and transporting 

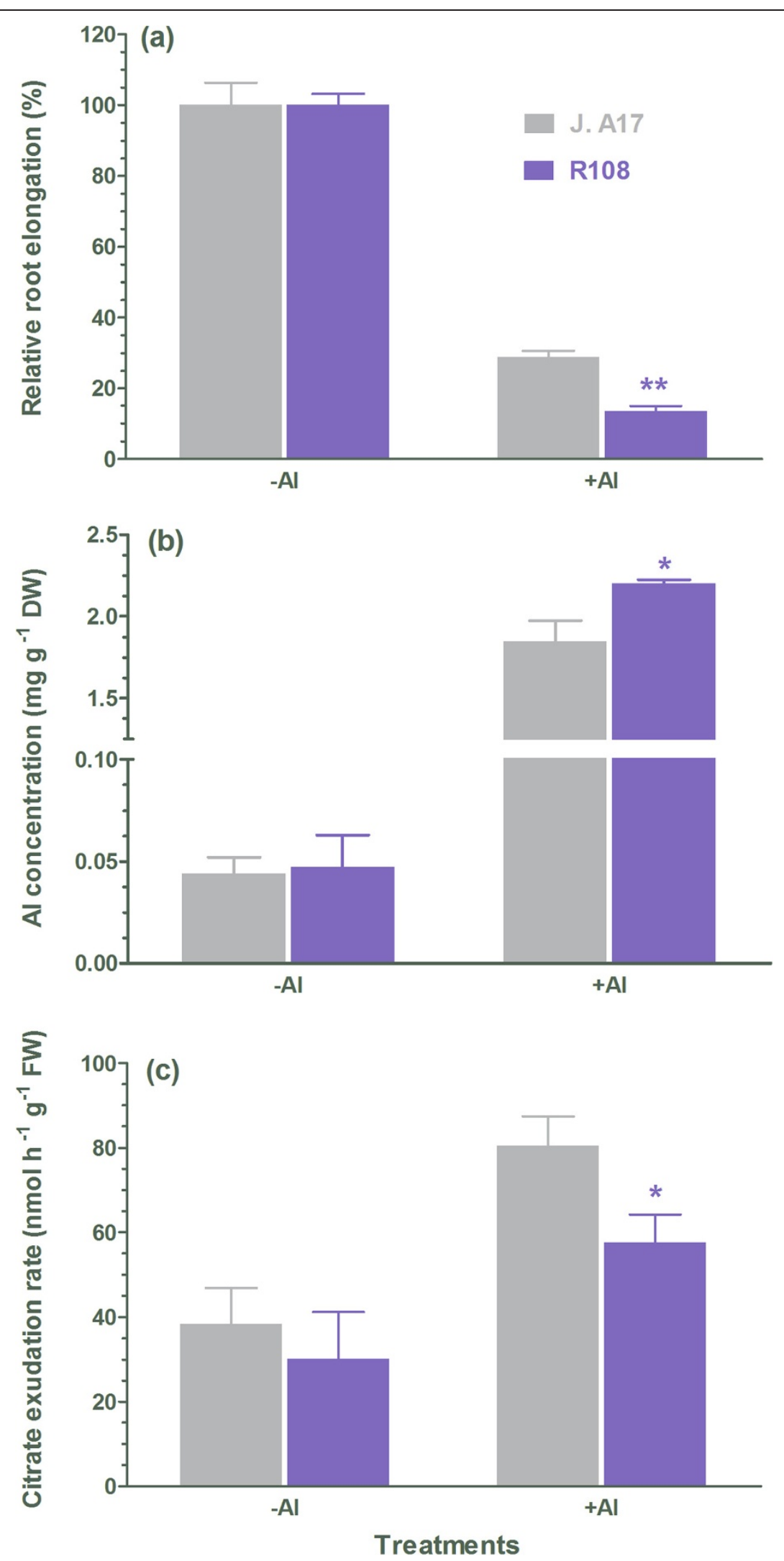

Figure 1 (See legend on next page.) 
(See figure on previous page.)

Figure 1 Effect of $\mathrm{Al}^{3+}$ on root elongation, citrate exudation and Al content in roots of J. A17 and R108 plants. The relative root elongation was determined by exposing 3-d-old seedlings of J. 17 and $\mathrm{R} 108$ to $5 \mu \mathrm{M} \mathrm{AlCl}_{3}(\mathrm{pH}$ 4.5) for 2 days (a). Data are mean \pm s.e. with $n=10$. Al contents in roots of $\mathrm{J}$. A17 and R108 plants before and after exposure to $5 \mu \mathrm{M} \mathrm{AlCl}$ ( $\mathrm{pH}$ 4.5) for 2 days (b). Data are mean \pm s.e. with $n=4$. Citrate exudation rate from roots of J. A17 and R108 plants treated with $5 \mu \mathrm{M} \mathrm{AlCl}_{3}$ (pH 4.5) for $24 \mathrm{~h}$ (c). Data are mean \pm s.e. with $n=5$. ${ }^{*}$ and ${ }^{* *}$ indicate significant difference between genotypes within a given growth condition $(-\mathrm{Al}$ or $+\mathrm{Al})$ at $P \leq 0.05$ and $P \leq 0.01$, respectively.

of Fe from roots to shoots in J. A17 plants [16]. A similar result showing that ecotype J. A17 had higher foliar Fe contents than R108 when grown in Fe-deficient medium was observed in the present study (Figure 2d). These results show that the two ecotypes differ in their tolerance to toxicities of $\mathrm{Al}$ and $\mathrm{Na}$ as well as Fe deficiency by differently regulating citrate exudation, $\mathrm{Na}$ uptake and Fe transport, respectively.

\section{Resequencing of R108}

Paired-end sequencing method was employed to resequence the genome of M. truncatula ecotype R108, and about 4.64 Gb original sequencing data were generated.
High-quality reads of $4.28 \mathrm{~Gb}$ were obtained after initially processing. The genome of R108 is $17 \%$ smaller than that of J. A17 [29]. This led to a sequencing mean coverage and depth of approx. $72 \%$ and 11 -fold over the whole genome, respectively (Figure 3 and Additional file 1: Figure S1). The coverage of chromosome 5 was the greatest among the chromosomes. In addition, we found a similar coverage of chromosome 5 in a tetraploid Medicago falcata (unpublished results), suggesting that Chr 5 may be the most conserved in the genus of Medicago.

Structure variations (SVs), short insertions/deletions (indels) and single nucleotide polymorphisms (SNPs) were identified by aligning the high-quality sequences against

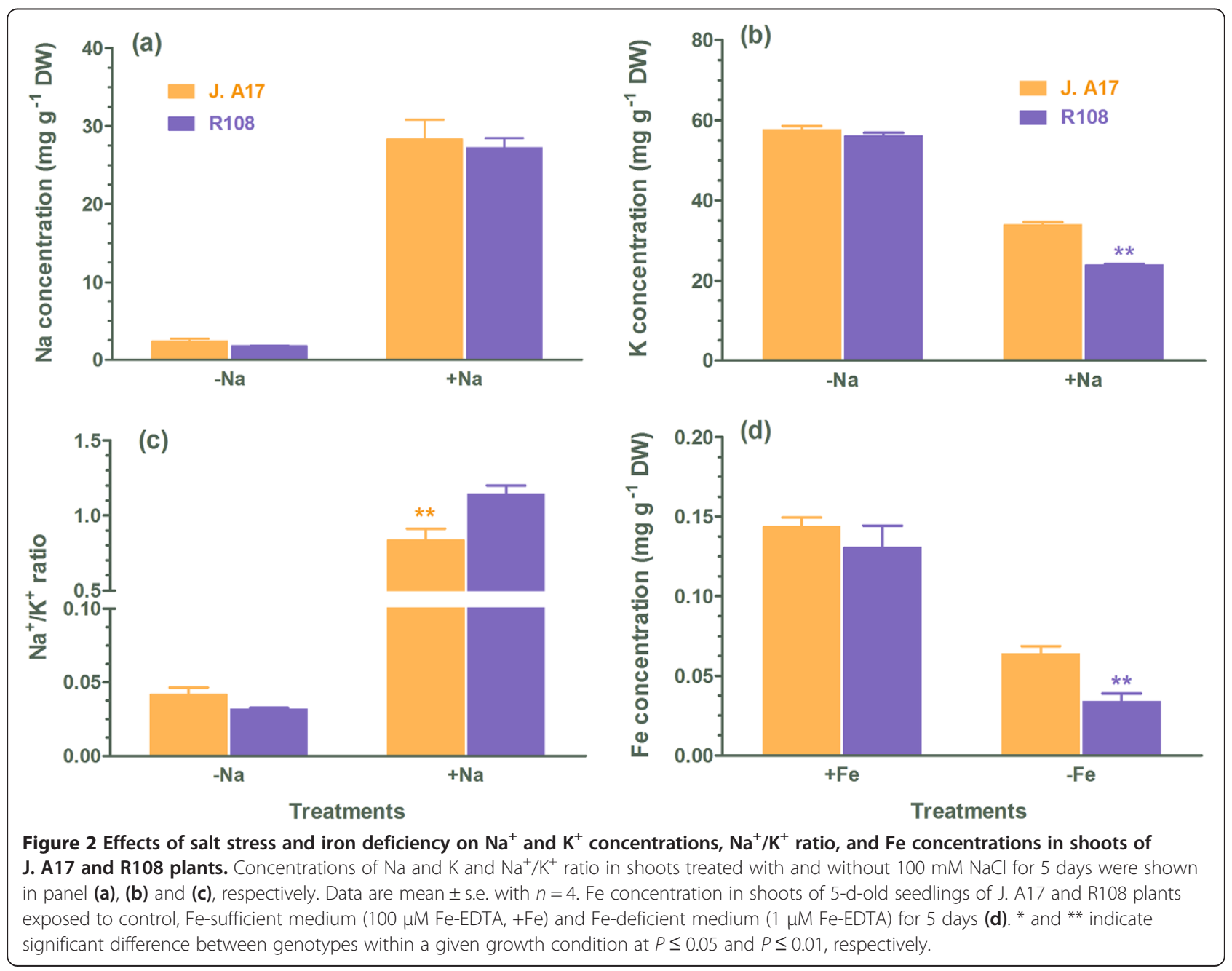




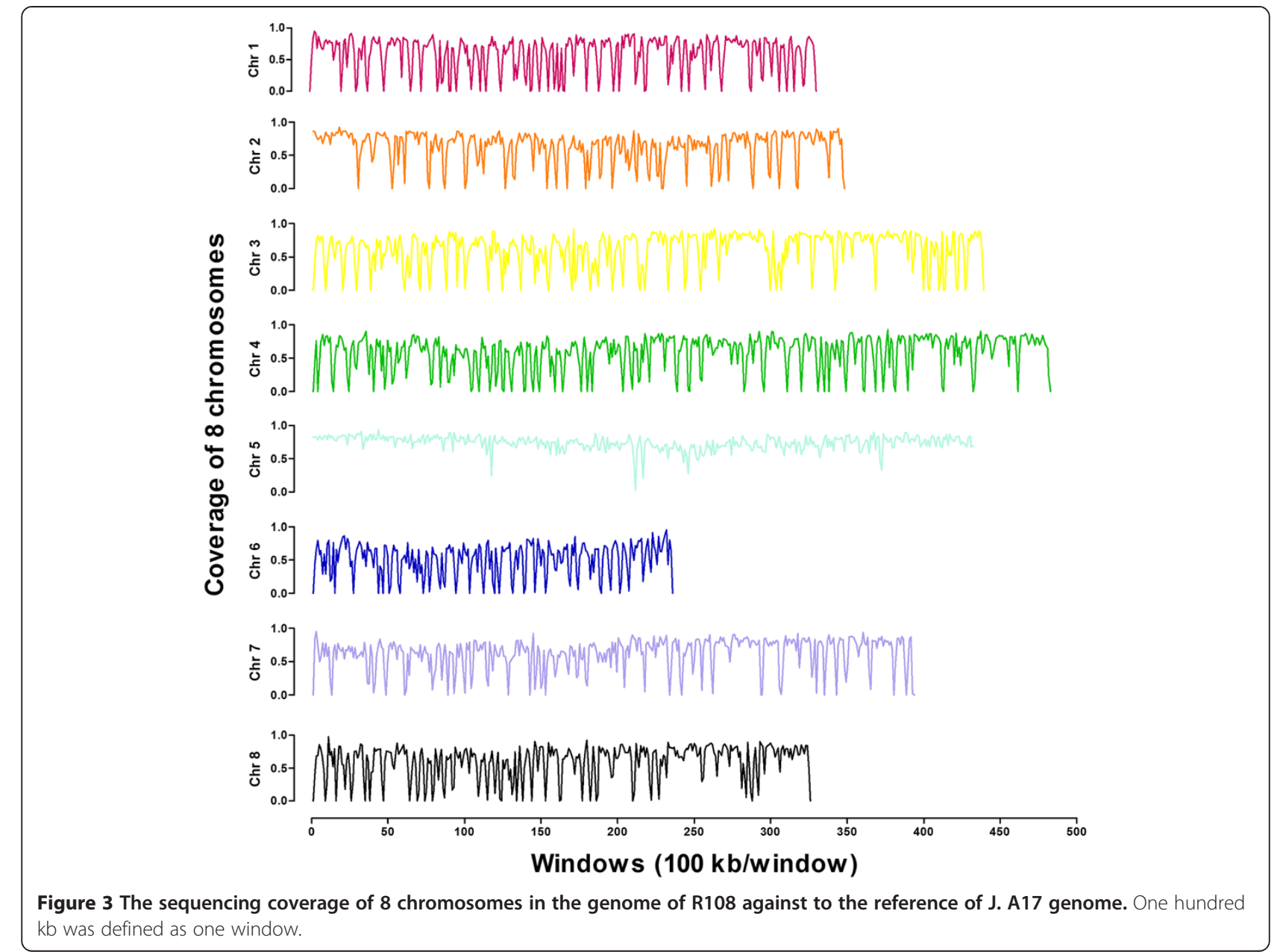

the reference genome of J. A17. We obtained a total of 12,750 SVs, 135,045 indels and 764,154 SNPs in the genome of R108 (Table 1).

Structure variations are important types of differences among individuals of the same species, and can cause large alterations to the genome, resulting in the differences in phenotypes. We identified 10,964 deletions,

Table 1 The number of SVs, indels and SNPs in the R108 genome

\begin{tabular}{lcc}
\hline \multicolumn{1}{c}{ Genome variations } & Numbers \\
\hline SV & Insertion & 1,239 \\
& Deletion & 10,964 \\
& Others & 547 \\
Indel & Insertion & 67,087 \\
& Deletion & 67,958 \\
SNP & Homozygosity & 660,168 \\
& Heterozygosity & 103,986
\end{tabular}

The data were obtained by mapping the reads of R108 obtained from resequencing to the reference genome of ecotype J. A17. SVs were separated into insertions, deletions and others. Indels were separated into insertions and deletions. SNPs were separated into homozygosity and heterozygosity.
1,239 insertions and 547 other SVs such as duplication, inversion and transposition by resequencing (Table 1). The quantity of deletions was more abundant than other SVs. This result is consistent with the forecast as the genome of R108 has been reported to be smaller than that of J. A17 [29]. We also identified 135,045 indels ranging from $1-5 \mathrm{bp}$ in length. Among these short indels, the number of insertions and deletions was almost equal (Table 1). Insertion of one bp and deletion of one bp were the mostly observed insertions and deletions, respectively, accounting for more than half of the total number of insertions and deletions (Additional file 1: Figure S2). Generally, genome variations were mainly accounted for by SNPs. Eighty-six percent of SNPs were homozygous over the whole genome (Table 1 ). For the SNPs within coding sequences, there were 70,695 nonsynonymous and 57,124 synonymous SNPs, respectively. This led to a ratio of nonsynonymous to synonymous nucleotide (Nonsyn/Syn) of 1.24. A similar ratio has been reported in soybean and rice, while the ratio in Arabidopsis (0.83) is smaller than our finding in the present study $[17,18,30]$. 


\section{Variations of mineral element-related genes}

The resequencing data obtained from $M$. truncatula ecotype R108 revealed that some genes involved in acquisition of mineral elements were deleted in R108 plants compared to ecotype J. A17 (Table 2).

Aluminum-induced exudation of citrate from roots that is mediated by membrane transporters can detoxify toxic $\mathrm{Al}^{3+}$ in the rhizosphere by forming non-toxic Alcitrate complex $[3,26,27]$. Several genes encoding the transporters of Al-induced citrate exudation belonging to MATE family have been identified [31-34]. Our resequencing data show that $771 \mathrm{bp}$ in the second intron of a gene encoding a putative aluminum-activated citrate transporter (MtAACT) was deleted (Table 2, Additional file 1: Figure S3). The sequence of MtAACT was similar with the known Al-induced citrate transporters (Figure 4a). Expression-level of MtAACT in J. A17 was higher than in $\mathrm{R} 108$ in the absence of $\mathrm{Al}^{3+}$, and it was up-regulated in both ecotypes by exposure to $\mathrm{AlCl}_{3}$ with the Al-induced expression of MtAACT in R108 being lower than in J. A17 plants (Figure 4b).

Previous studies have shown that R108 is more sensitive to salt stress than J. A17, and real-time qPCR showed that expression of MtZpt2-1 is greater in J. A17 than in R108 plants [14]. Overexpression of MtZpt2-1 in roots of the salt-sensitive ecotype of $M$. truncatula confers enhanced tolerance to salt stress, suggesting that differential expression of $M t Z p t 2-1$ is responsible for the difference in adaptation to salt stress. Resequencing allowed us to analyze the promoter sequence of $M t Z p t 2-1$ in R108 plants. Stress-responsive-related cis-elements were identified by PLACE database between J. A17 and R108 (Figure 5). The number of MYC and W-box elements was greater in J. A17 than in R108, which may underpin the higher expression levels of MtZpt2-1 in J. A17 than in R108 plants under conditions of salt stress.

YSLs (Yellow Stripe-Likes) are involved in longdistance transport of Fe in plants [35,36]. There are five YSLs in the genome of $M$. truncatula according to Mt3.5 assembly of the reference genome. Our resequencing results show that an YSL gene (Medtr1g007540) was deleted in the genome of R108 (Table 2). The protein encoded by Medtr1g007540 is highly similar to Arabidopsis AtYSL3 (At5g53550) (Figure 6). The deletion of the YSL gene in the genome of R108 may account for the less accumulation of iron in the shoots of R108 (Figure 2d).

\section{Discussion}

Identification of genome variations using resequencing

Analyses of gene expression by methods such as transcriptome, microarray and DGE have been used to decipher the differential responses among species and cultivars/ ecotypes with close genetic background to abiotic stresses [14,37-40]. However, these methods are less effective when several mechanisms underlie the different responses to abiotic stresses. Moreover these methods cannot be used to analyze cis-acting regulatory elements. In contrast, resequencing technology can identify genome variations which are responsible for morphological and physiological differences [41]. In addition, cis-acting regulatory sequences obtained from the resequencing can be used to pinpoint the differential expression in response to abiotic stresses. Estimation of phylogenetic relationships among Medicago species by genome resequencing has been reported [42]. However, genome resequencing has not been used to investigate responses of Medicago species to abiotic stresses in general and mineral stresses in particular so far. In the present study, we utilized this technology to decipher the mechanisms underlying the different responses of two $M$. truncatula ecotypes to aluminum toxicity, salt stress and iron deficiency.

\section{Tolerance of $M$. truncatula to $\mathrm{Al}$ is achieved by citrate exudation}

Aluminum is the most abundant metal in the earth's crust. Phytotoxic $\mathrm{Al}^{3+}$ is solubilized when soil becomes acidified. Inhibition of root elongation is one of the earliest and most distinct symptoms exhibited by plants suffering from Al toxicity [43]. Plants have evolved numerous mechanisms to adapt to Al toxicity. Exudation of organic anions from root apices to chelate toxic $\mathrm{Al}^{3+}$ in the rhizosphere is an effective way to detoxify $\mathrm{Al}$ toxicity, thus conferring tolerance to $\mathrm{Al}$ toxicity [3,26,27]. Several Al-activated citrate transporters have been shown to be involved in regulation of $\mathrm{Al}$ tolerance. For instance, SbMATE in sorghum (Sorghum bicolor) and HvAACT1 in barley (Hordeum vulgare) that belong to the multidrug and toxic compound exudation (MATE) family have been identified to mediate $\mathrm{Al}$-activated citrate exudation. Heterologous expression of SbMATE in Arabidopsis and $H v A A C T 1$ in tobacco leads to enhanced citrate efflux, thus conferring tolerance to Al toxicity [31,32]. The homologs in Arabidopsis and maize have subsequently been cloned [33,34].

Table 2 Deleted genes related to mineral stress in the genome of $M$. truncatula ecotype R108 plants

\begin{tabular}{cccc}
\hline Genes & Positions in reference & Annotations & Positions of deletions \\
\hline Medtr8g036660 & MtChr8: 8363576-8369153 (-) & Putative aluminum activated citrate transporter & MtChr8: 8367361-8368131 \\
Medtr1g007540 & MtChr1: 996073-999271 (-) & Metal-nicotianamine transporter YSL3 & MtChr1:980798-1010225
\end{tabular}

The data were obtained by mapping the reads of R108 obtained from resequencing to the reference genome of ecotype J. A17. 


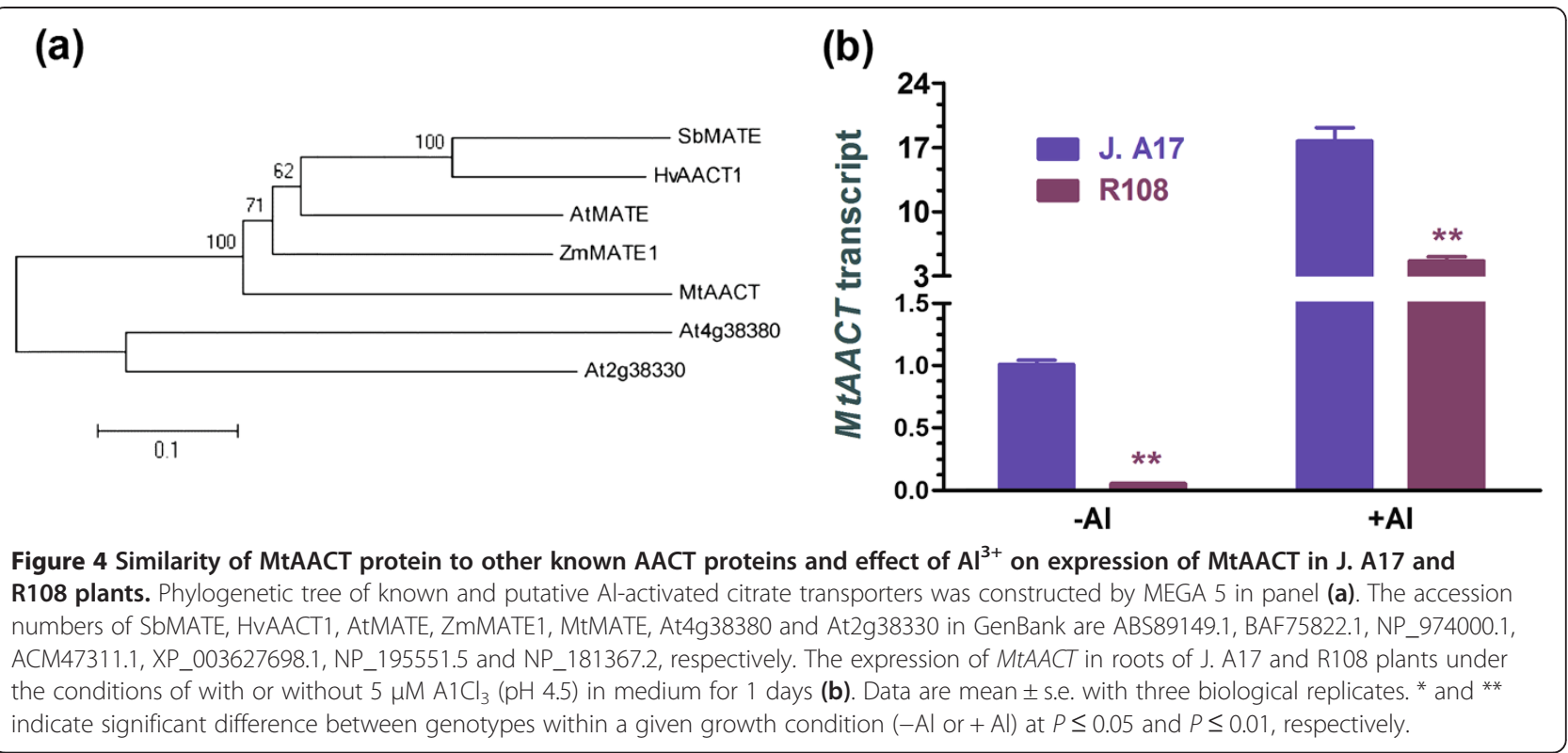

In the present study, we found that root elongation of R108 was more inhibited by Al than that of J. A17 plants (Figure 1a), suggesting that R108 is more sensitive to $\mathrm{Al}$ than J. A17. We uncovered deletion of partial sequence in the second intron of a gene encoding a putative Alactivated citrate transporter (MtAACT) in R108 plants by resequencing (Table 2). The amino acid sequence of this transporter is similar with the known Al-activated citrate transporters in other plant species (Figure 4a). In addition, expression of this gene was up-regulated by $\mathrm{Al}$ in both ecotypes with the magnitude of $\mathrm{Al}$-induced expression of MtAACT in R108 less than in J. A17 plants (Figure 4b), suggesting that expression of $M t A A C T$ is sensitive to $\mathrm{Al}^{3+}$. The suppressed expression of MtAACT in R108 relative to that in J. A17 plants is likely to be accounted for by the deletion of the partial sequence of the second intron. The intron deleted in R108 plants may activate gene expression by enhancers within introns and/or regulating chromatin remodeling. Several introns in plants are reported to increase the expression of genes. For example, the second intron from Arabidopsis agamous gene can function in both orientations to drive expression of reporter gene from a minimal promoter [44]. The first intron of Arabidopsis gene encoding elongation factor eEF-1 $\beta$ has the similar function to enhance gene expression [45]. The lower abundance of $M t A A C T$ transcripts in R108 than J. A17 when exposed to solution containing toxic $\mathrm{Al}^{3+}$ may explain the less citrate released from roots of R108 than J. A17 plants in response to $\mathrm{Al}$ treatment (Figure 1c). The reduced citrate exudation from roots of R108 plants due to reduced expression of MtAACT would render R108 plants less effective to complex toxic $\mathrm{Al}^{3+}$ in the rhizosphere, thus making it less tolerant to $\mathrm{Al}$ than J. A17 plants. The greater accumulation of $\mathrm{Al}$ in roots of $\mathrm{R} 108$ than in those of J. A17 is in line with this argument (Figure 1b).

\section{Promoter analysis of MtZpt2-1}

The ecotype J. A17 plants have been shown to be more tolerant to salt stress than R108 plants $[14,15]$. A gene encoding a TFIIIA-related transcription factor, MtZpt2-1 has been identified by its greater up-regulation in J. A17 than R108 plants under salt stress [14]. MtZpt2-1 can active the expression of many stress-responsive genes [46]. Several stress-related cis-elements were found by analyzing the promoter sequences of $M t Z p t 2-1$ in both ecotypes (Figure 5). These stress-related cis-elements in MtZpt2-1 can allow this gene to be up-regulated in response to abiotic stresses, thus participating in the regulation of tolerance to abiotic stresses. Two MYB-core

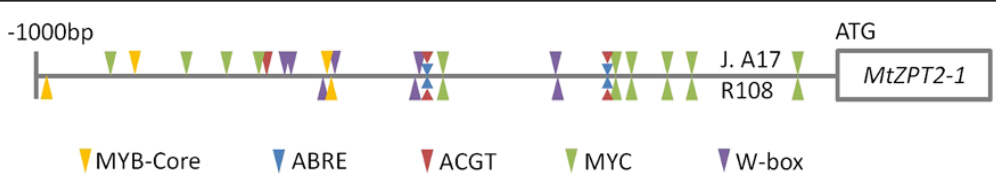

Figure 5 Analysis of MtZpt2-1 promoter sequence of J. A17 and R108. The arrows above line represent cis-elements of J. A17, and that of below the line indicate elements of R108. 


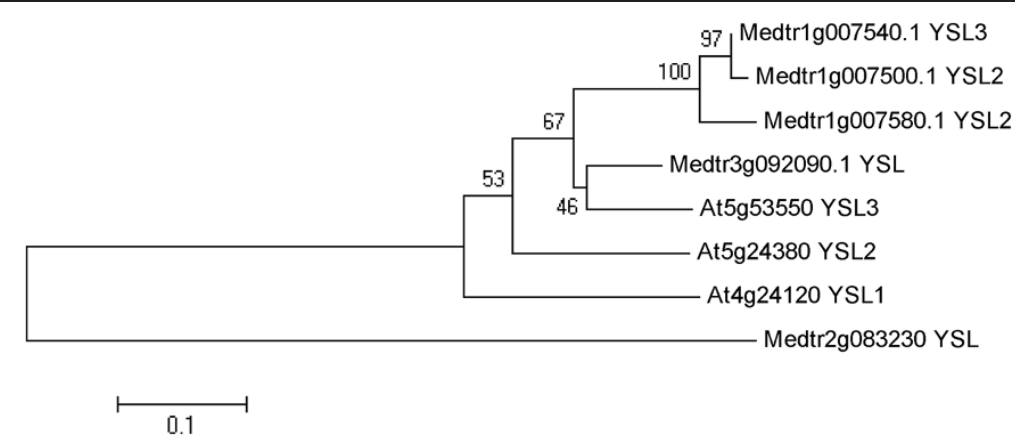

Figure 6 Sequence analysis of YSL protein family. Phylogenetic tree of these proteins was constructed by MEGA 5. The corresponding IDs were shown in the figure.

elements and ABA-responsive elements (ABRE) have been shown to be involved in responses to osmotic stress and ABA, respectively $[47,48]$. However, the two ecotypes differed in their promoter sequences of $M t Z p t 2-1$, such that MtZpt2-1 of J. A17 plants had one more ACGT element, four more MYC elements and two more W-box elements than R108 plants. There are reports showing the involvements of these cis-elements in stress response [49-51]. The greater number of cis-elements of MtZpt2-1 in J. A17 plants may explain higher expression of MtZpt2-1 in J. A17 plants than in R108 plants under conditions of salt stress, thus conferring their tolerance to salt stress.

\section{Function of YSL in iron transport}

YS1 (Yellow Stripe 1) has been identified to be involved in uptake of iron from soil by roots in maize [52,53]. Based on their sequence similarity to the maize YS1, eight YSLs (Yellow Stripe-Likes) were identified in Arabidopsis. AtYSL1, AtYSL2 and AtYSL3 are expressed most strongly in the vascular parenchyma cells [36,54]. The ysl1ysl3 double mutant displays strong interveinal chlorosis, and has reduced foliar iron content [36]. These findings suggest that YSLs act as key mediators in unloading iron to mesophyll cell after iron is transported from roots through xylem in plants [55].

Five YSLs were identified in the genome of Medicago according to Mt3.5. However, in the genome of R108, an YSL gene (Medtr1g007540) was deleted (Table 2). The protein encoded by the YSL gene had high similarity with AtYSL3 of Arabidopsis (Figure 6). We hypothesize that this protein may be involved in unloading of iron from the vascular tissues to mesophyll cells. The deletion of this gene in R108 plants would impair iron unloading to mesophyll cells, thus leading to the reduced iron contents in shoots of R108 plants when grown in iron-deficient medium (Figure 2d).

\section{Conclusions}

The two $M$. truncatula ecotypes Jemalong A17 and R108 differed in their sensitivity to aluminum toxicity, salt stress and iron deficiency. Resequencing of $M$. truncatula ecotype R108 uncovered a total of 12,750 SVs, 135,045 indels and 764,154 SNPs by comparing with the reference genome of $\mathrm{J}$. A17. We found that the partial sequence of the second intron of $M t A A C T$ that encodes a putative Al-activated citrate transporter was deleted. This partial deletion may lead to the lower expression level of $M t A C C \mathrm{~T}$ in $\mathrm{R} 108$ plants than that in J. A17 plants in the absence and presence of toxic $\mathrm{Al}$ in the growth medium. The reduced expression of MtAACT in R108 plants in turn may render less exudation of citrate form roots to detoxify $\mathrm{Al}$ in the rhizosphere, thus making R108 plants less tolerance to Al than J. A17 plants. In addition, we demonstrated that promoter sequence in MtZpt2-1 of J. A17 plants contained more responseelements than that of R108 plants. Given the regulatory roles of $M t Z p t 2-1$ in response to salt stress, these results may account for the greater tolerance of J. A17 plants to salt stress than R108 plants. Finally, our results revealed that deletion of an YSL gene encoding an iron transporter in the genome of R108 plants is likely to impair long-distance transport of iron in R108 plants. This result may explain the greater sensitivity of R108 plants to iron deficiency than J. A17 plants. Taken together, these findings demonstrate that analyses of genome variations by sequencing can shed important light on differences in responses of $M$. truncatula ecotypes to abiotic stress in general and mineral stress in particular.

\section{Methods}

\section{Plant materials and treatments}

Two Medicago truncatula ecotypes Jemalong A17 and R108 were used in this study. Seeds of both ecotypes were treated with concentrated sulfuric acid for $8 \mathrm{~min}$, and then thoroughly rinsed with water. After chilled at $4^{\circ} \mathrm{C}$ for $2 \mathrm{~d}$, seeds were sown on $0.8 \%$ agar to germinate at $25^{\circ} \mathrm{C}$ until the radicals were approximately $2 \mathrm{~cm}$. The seeds were planted in the same plastic buckets ( 6 seedlings for both ecotypes per bucket) filled with $2.5 \mathrm{~L}$ aerated nutrient solution. The composition of full-strength 
nutrient solution is: $2.5 \mathrm{mM} \mathrm{KNO} 3,0.5 \mathrm{mM} \mathrm{KH}_{2} \mathrm{PO}_{4}$, $0.25 \mathrm{mM} \mathrm{CaCl}_{2}, 1 \mathrm{mM} \mathrm{MgSO}{ }_{4}, 100 \mu \mathrm{M}$ Fe-Na-EDTA, $30 \mu \mathrm{M} \mathrm{H} \mathrm{H}_{3} \mathrm{BO}_{3}, 5 \mu \mathrm{M} \mathrm{MnSO}, 1 \mu \mathrm{M} \mathrm{ZnSO}, 1 \mu \mathrm{M}$ $\mathrm{CuSO}_{4}$ and $0.7 \mu \mathrm{M} \mathrm{Na}_{2} \mathrm{MoO}_{4}$ with $\mathrm{pH}$ of 6.0.

For measurements of the effect of $\mathrm{AlCl}_{3}$ on root elongation, 3-d-old seedlings were transferred into solutions containing $0.5 \mathrm{mM} \mathrm{CaCl}_{2}$ with and without $5 \mu \mathrm{M} \mathrm{AlCl}_{3}$ $(\mathrm{pH} 4.5)$ for 2 days. Length of primary root was measured after treatment with $\mathrm{AlCl}_{3}$, and relative root elongation was calculated. To determine the effect of $\mathrm{AlCl}_{3}$ on exudation of citrate from roots, three-week-old seedlings were transferred into solutions containing $0.2 \mathrm{mM}$ $\mathrm{CaCl}_{2}$ with and without $5 \mu \mathrm{M} \mathrm{AlCl}_{3}$ (pH 4.5) for 1 days. The exudation from the treated roots was collected at room temperature without light for 2 hours, and then citrate concentration in the exudation solution was determined by reversed-phase high performance liquid chromatography (HPLC) as described previously [56]. For measurements of $\mathrm{Al}$ content in roots, seedlings of the two ecotypes were treated with $5 \mu \mathrm{M} \mathrm{AlCl}$ ( for $24 \mathrm{~h}$, and roots were collected for measurement of $\mathrm{Al}$.

Three-week-old seedlings were transferred into solutions containing $100 \mathrm{mM} \mathrm{NaCl}$ or $1 \mu \mathrm{M}$ Fe-Na-EDTA for 5 days. Shoots were collected to measure the content of $\mathrm{Na}^{+}, \mathrm{K}^{+}$and Fe.

\section{Measurement of mineral elements}

Plant materials treated with and without mineral stress (Al and $\mathrm{Na}$ toxicity and Fe deficiency) were harvested and dried at $80^{\circ} \mathrm{C}$ to constant weight. As much as $50 \mathrm{mg}$ of dry plant material was weighed and placed in a digestion tube, and then samples were digested with $6 \mathrm{~mL}$ of nitric acid and $2 \mathrm{~mL}$ of hydrogen peroxide using microwave system (MARS, CEM). The digest were diluted to $50 \mathrm{~mL}$. After filtering, the concentrations of $\mathrm{Al}, \mathrm{Na}, \mathrm{K}$ and Fe were measured by ICP-AES (Thermo).

\section{DNA isolation and resequencing}

DNA isolation was carried out using a CTAB (cetyl trimethylammonium bromide) protocol. After quality assay, genomic DNA was fragmented randomly. After electrophoresis, DNA fragments of about 500 bp were gel purified. Adapter ligation and DNA cluster preparation were performed and subjected to $2 \times 90$ bp paired-end sequencing on an Illumina Hiseq2000 sequencer. The raw data have been submitted to NCBI Sequence Read Archive (http://www.ncbi.nlm.nih.gov/sra) and the accession number is SRP029924.

\section{Bioinformatics analysis}

Firstly, adapter contamination in the raw data was removed. To ensure quality, each base in a read was assigned a quality score $(\mathrm{Q})$ by a phred-like algorithm
$[57,58]$. The reads which contained more than 50\% low quality bases $(\mathrm{Q} \leq 5)$ were removed. Using SOAP2 [59], all reads were aligned with the $M$. truncatula reference genome (Mt 3.5 assembly) [10]. If the original read could not be aligned onto the reference sequence, the first nucleotides at 5 ' end and two nucleotides at 3 ' end were deleted, and then aligned onto the reference again. If the sequence failed to alignment, two more nucleotides at 3' end were deleted. The procedure was repeated until alignment was achieved or the read was less than $32 \mathrm{bp}$. The average sequencing depth and coverage was calculated using the results of alignment.

Structure variations, short indels and SNPs were identified by aligning the reads of R108 obtained from resequencing to the reference genome of ecotype J. A17. In our experiment, the distance of both relevant paired-end reads should be about $500 \mathrm{bp}$. However, if the distance and orientation were different from expectation after both relevant paired-end reads were aligned with the reference genome, the region might have variation structures. The types of structure variations that can be detected include deletion, insertion, duplication, inversion and transposition. SOAPsv was used to identify structure variation, and at least three paired-end reads were needed to confirm a variation structure in the present study. The alignment gaps in mapped reads were identified as candidate indels using SOAPindel. The maximum gap length was $5 \mathrm{bp}$, and at least three pairs of reads to define an indel. On the basis of alignment, polymorphic loci against the reference sequence were identified according to the following criteria: $Q \geq 20,3 \leq$ Depth $\leq 100$ and at least 5 bp away from each other. SOAPsnp was used in this assay.

Plant cis-acting regulatory elements were searched by the PLACE database [60].

\section{RNA isolation and real-time quantitative PCR}

Total RNA was isolated using RNAiso Plus reagent (TaKaRa) and treated with RNase-free DNase I (Promega). The total RNA was reverse-transcribed into first-strand cDNA with PrimeScript ${ }^{\circledR}$ RT reagent Kit (TaKaRa).

Real-time quantitative PCR (RT-qPCR) was performed using ABI Stepone Plus instrument. Gene-specific primers of MtAACT (accession No. XM_003627650.1) were 5'-GAC ATA GAG AAA GGG ACA-3' and 5'AGG ATA GTA AAT GGG GTT-3'. MtActin (accession No. BT141409) and MtGADPH (accession No. XM_ 003608827.1) were used as internal control with primers: (5'-ACG AGC GTT TCA GAT G-3' and 5'-ACC TCC GAT CCA GAC A-3') and (5'- AAG GAG GAG TCT GAG GGC-3' and 5'-AAC GGC TGC TAG GCT AAT$3 ')$. Each reaction contained $5.0 \mu \mathrm{L}$ of SYBR Green 
Master Mix reagent (TOYOBO), $0.4 \mu \mathrm{L}$ cDNA samples, and $0.6 \mu \mathrm{L}$ of $10 \mu \mathrm{M}$ gene-specific primers in a final volume of $10 \mu \mathrm{L}$. The thermal cycle used was $95^{\circ} \mathrm{C}$ for $2 \mathrm{~min}, 40$ cycles of $95^{\circ} \mathrm{C}$ for $30 \mathrm{~s}, 55^{\circ} \mathrm{C}$ for $30 \mathrm{~s}$, and $72^{\circ} \mathrm{C}$ for $30 \mathrm{~s}$. The relative expression level was calculated by the comparative $\mathrm{C}_{\mathrm{T}}$ method.

\section{Additional file}

\section{Additional file 1: Figure S1. The R108 sequencing depth of 8} chromosomes against to the reference J. A17. One hundred kb was defined as one window. The points with depth more than 15 were hided to make the figure clearer. Figure S2. The number of indels varying from 1 to $5 \mathrm{bp}$ in the genome of R108. The number of insertions and deletions varying from 1 to 5 bp was shown in panel (a) and (b), respectively. The "I" and "D" mean insertion and deletion, respectively. Figure S3. The structure of the MtAACT genomic region. The exons and introns are drawn as rectangles and lines, respectively. The region with red crosses is deleted in the genome of R108.

\section{Competing interests}

The authors declare that they have no competing interests.

\section{Authors' contributions}

TZW WHZ designed the experiments; TZW conducted the experiments; TZW QYT BLW MGZ WHZ analyzed the data; TZW WHZ wrote the paper. All authors read and approved the final manuscript.

\section{Acknowledgements}

This study was supported by the National Natural Science Foundation of China $(31272234,31300231)$ and State Key Laboratory of Vegetation and Environmental Change (2014ZDFX04).

Received: 6 January 2014 Accepted: 30 April 2014

Published: 6 May 2014

\section{References}

1. Graham PH, Vance CP: Legumes: Importance and constraints to greater use. Plant Physiol 2003, 131(3):872-877.

2. Cook DR: Medicago truncatula - a model in the making! Commentary. Curr Opin Plant Biol 1999, 2(4):301-304.

3. Ma JF, Ryan PR, Delhaize E: Aluminium tolerance in plants and the complexing role of organic acids. Trends Plant Sci 2001, 6(6):273-278.

4. Thimm O, Essigmann B, Kloska S, Altmann T, Buckhout TJ: Response of arabidopsis to iron deficiency stress as revealed by microarray analysis. Plant Physio/ 2001, 127(3):1030-1043.

5. Munns R, Tester M: Mechanisms of salinity tolerance. Annu Rev Plant Biol 2008, 59:651-681.

6. Branca A, Paape TD, Zhou P, Briskine R, Farmer AD, Mudge J, Bharti AK, Woodward JE, May GD, Gentzbittel L, Ben C, Denny R, Sadowsky MJ, Ronfort J, Bataillon T, Young ND, Tiffin P: Whole-genome nucleotide diversity, recombination, and linkage disequilibrium in the model legume Medicago truncatula. Proc Natl Acad Sci U S A 2011, 108(42):E864-E870.

7. Ellwood SR, D'Souza NK, Kamphuis LG, Burgess TI, Nair RM, Oliver RP. SSR analysis of the Medicago truncatula SARDI core collection reveals substantial diversity and unusual genotype dispersal throughout the Mediterranean basin. Theor App/ Genet 2006, 112(5):977-983.

8. Rodriguez-Celma J, Lin WD, Fu GM, Abadia J, Lopez-Millan AF, Schmidt W: Mutually exclusive alterations in secondary metabolism are critical for the uptake of insoluble iron compounds by Arabidopsis and Medicago truncatula. Plant Physiol 2013, 162(3):1473-1485.

9. Wang T, Chen L, Zhao M, Tian Q, Zhang WH: Identification of drought-responsive microRNAs in Medicago truncatula by genome-wide high-throughput sequencing. BMC Genomics 2011, 12:367.

10. Young ND, Debelle F, Oldroyd GED, Geurts R, Cannon SB, Udvardi MK, Benedito VA, Mayer KFX, Gouzy J, Schoof H, Van de Peer Y, Proost S, Cook DR, Meyers BC, Spannagl M, Cheung F, De Mita S, Krishnakumar V, Gundlach H, Zhou SG, Mudge J, Bharti AK, Murray JD, Naoumkina MA,
Rosen B, Silverstein KAT, Tang HB, Rombauts S, Zhao PX, Zhou P: The Medicago genome provides insight into the evolution of rhizobial symbioses. Nature 2011, 480(7378):520-524.

11. Hoffmann B, Trinh TH, Leung J, Kondorosi A, Kondorosi E: A new Medicago truncatula line with superior in vitro regeneration, transformation, and symbiotic properties isolated through cell culture selection. Mol Plant Microbe In 1997, 10(3):307-315.

12. Gaige AR, Doerksen T, Shuai B: Medicago truncatula ecotypes A17 and R108 show variations in jasmonic acid/ethylene induced resistance to Macrophomina phaseolina. Can J Plant Pathol 2012, 34(1):98-103.

13. Salzer P, Feddermann N, Wiemken A, Boller T, Staehelin C: Sinorhizobium meliloti-induced chitinase gene expression in Medicago truncatula ecotype R108-1: a comparison between symbiosis-specific class $V$ and defence-related class IV chitinases. Planta 2004, 219(4):626-638.

14. de Lorenzo L, Merchan F, Blanchet S, Megias M, Frugier F, Crespi M, Sousa C: Differential expression of the TFIIIA regulatory pathway in response to salt stress between Medicago truncatula genotypes. Plant Physiol 2007, 145(4):1521-1532.

15. Merchan F, Breda C, Hormaeche JP, Sousa C, Kondorosi A, Aguilar OM Megias M, Crespi M: A Kruppel-like transcription factor gene is involved in salt stress responses in Medicago spp. Plant Soil 2003, 257(1):1-9.

16. Li G, Wang BL, Tian QY, Wang TZ, Zhang WH: Medicago truncatula ecotypes A17 and R108 differed in their response to iron deficiency. J Plant Physiol 2014, 171:639-647.

17. McNally KL, Childs KL, Bohnert R, Davidson RM, Zhao K, Ulat VJ, Zeller G, Clark RM, Hoen DR, Bureau TE, Stokowski R, Ballinger DG, Frazer KA, Cox DR, Padhukasahasram B, Bustamante CD, Weigel D, Mackill DJ, Bruskiewich RM, Ratsch G, Buell CR, Leung H, Leach JE: Genomewide SNP variation reveals relationships among landraces and modern varieties of rice. Proc Natl Acad Sci U S A 2009, 106(30):12273-12278.

18. Clark RM, Schweikert G, Toomajian C, Ossowski S, Zeller G, Shinn P, Warthmann N, Hu TT, Fu G, Hinds DA, Chen HM, Frazer KA, Huson DH, Schoelkopf B, Nordborg M, Raetsch G, Ecker JR, Weigel D: Common sequence polymorphisms shaping genetic diversity in Arabidopsis thaliana. Science 2007, 317(5836):338-342.

19. Lai JS, Li RQ, Xu X, Jin WW, Xu ML, Zhao HN, Xiang ZK, Song WB, Ying K, Zhang M, Jiao YP, Ni PX, Zhang JG, Li D, Guo XS, Ye KX, Jian M, Wang B, Zheng HS, Liang HQ, Zhang XQ, Wang SC, Chen SJ, Li JS, Fu Y, Springer NM, Yang HM, Wang JA, Dai JR, Schnable PS: Genome-wide patterns of genetic variation among elite maize inbred lines. Nat Genet 2010, 42(11):1027-U1158.

20. Borevitz JO, Liang D, Plouffe D, Chang HS, Zhu T, Weigel D, Berry CC, Winzeler E, Chory J: Large-scale identification of single-feature polymorphisms in complex genomes. Genome Res 2003, 13(3):513-523.

21. Bruce M, Hess A, Bai JF, Mauleon R, Diaz MG, Sugiyama N, Bordeos A, Wang GL, Leung $H$, Leach JE: Detection of genomic deletions in rice using oligonucleotide microarrays. BMC Genomics 2009, 10:129.

22. Amtmann A: Learning from evolution: Thellungiella generates new knowledge on essential and critical components of abiotic stress tolerance in plants. Mol Plant 2009, 2(1):3-12.

23. Wong CE, Li Y, Labbe A, Guevara D, Nuin P, Whitty B, Diaz C, Golding GB, Gray GR, Weretilnyk EA, Griffith M, Moffatt BA: Transcriptional profiling implicates novel interactions between abiotic stress and hormonal responses in Thellungiella, a close relative of Arabidopsis. Plant Physiol 2006, 140(4):1437-1450.

24. Gong QQ, Li PH, Ma SS, Rupassara SI, Bohnert HJ: Salinity stress adaptation competence in the extremophile Thellungiella halophila in comparison with its relative Arabidopsis thaliana. Plant J 2005, 44(5):826-839

25. Wu HJ, Zhang ZH, Wang JY, Oh DH, Dassanayake M, Liu BH, Huang QF, Sun HX, Xia R, Wu YR, Wang YN, Yang Z, Liu Y, Zhang WK, Zhang HW, Chu JF, Yan CY, Fang S, Zhang JS, Wang YQ, Zhang FX, Wang GD, Lee SY, Cheeseman JM, Yang BC, Li B, Min JM, Yang LF, Wang J, Chu CC: Insights into salt tolerance from the genome of Thellungiella salsuginea. Proc Natl Acad Sci U S A 2012, 109(30):12219-12224.

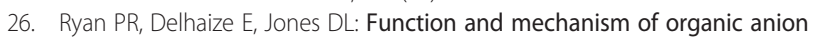
exudation from plant roots. Annu Rev Plant Phys 2001, 52:527-560.

27. Ma JF: Role of organic acids in detoxification of aluminum in higher plants. Plant Cell Physiol 2000, 41(4):383-390.

28. Tester $\mathrm{M}$, Davenport $\mathrm{R}: \mathrm{Na}^{+}$tolerance and $\mathrm{Na}^{+}$transport in higher plants. Ann Bot-London 2003, 91(5):503-527. 
29. Blondon F, Marie D, Brown S, Kondorosi A: Genome size and base composition in Medicago sativa and M. truncatula species. Genome 1994 37(2):264-270

30. Lam HM, Xu X, Liu X, Chen WB, Yang GH, Wong FL, Li MW, He WM, Qin N, Wang B, Li J, Jian M, Wang JA, Shao GH, Wang J, Sun SSM, Zhang GY: Resequencing of 31 wild and cultivated soybean genomes identifies patterns of genetic diversity and selection. Nat Genet 2010, 42(12):1053-U1041.

31. Furukawa J, Yamaji N, Wang H, Mitani N, Murata Y, Sato K, Katsuhara M, Takeda K, Ma JF: An aluminum-activated citrate transporter in barley. Plant Cell Physiol 2007, 48(8):1081-1091.

32. Magalhaes JV, Liu J, Guimaraes CT, Lana UGP, Alves VMC, Wang YH, Schaffert RE, Hoekenga OA, Pineros MA, Shaff JE, Klein PE, Carneiro NP, Coelho CM, Trick HN, Kochian LV: A gene in the multidrug and toxic compound extrusion (MATE) family confers aluminum tolerance in sorghum. Nat Genet 2007, 39(9):1156-1161.

33. Liu JP, Magalhaes JV, Shaff J, Kochian LV: Aluminum-activated citrate and malate transporters from the MATE and ALMT families function independently to confer Arabidopsis aluminum tolerance. Plant J 2009, 57(3):389-399.

34. Maron LG, Pineros MA, Guimaraes CT, Magalhaes JV, Pleiman JK, Mao CZ Shaff J, Belicuas SNJ, Kochian LV: Two functionally distinct members of the MATE (multi-drug and toxic compound extrusion) family of transporters potentially underlie two major aluminum tolerance QTLs in maize. Plant J 2010, 61(5):728-740.

35. Curie C, Cassin G, Couch D, Divol F, Higuchi K, Jean M, Misson J, Schikora A, Czernic P, Mari S: Metal movement within the plant: contribution of nicotianamine and yellow stripe 1-like transporters. Ann Bot-London 2009, 103(1):1-11

36. Waters BM, Chu HH, DiDonato RJ, Roberts LA, Eisley RB, Lahner B, Salt DE, Walker EL: Mutations in Arabidopsis Yellow Stripe-Like1 and Yellow Stripe-Like3 reveal their roles in metal ion homeostasis and loading of metal ions in seeds. Plant Physiol 2006, 141(4):1446-1458.

37. Fowler S, Thomashow MF: Arabidopsis transcriptome profiling indicates that multiple regulatory pathways are activated during cold acclimation in addition to the CBF cold response pathway. Plant Cell 2002 . 14(8):1675-1690.

38. Hao QN, Zhou XA, Sha AH, Wang C, Zhou R, Chen SL: Identification of genes associated with nitrogen-use efficiency by genome-wide transcriptional analysis of two soybean genotypes. BMC Genomics 2011, 12:525.

39. Alba R, Fei ZJ, Payton P, Liu Y, Moore SL, Debbie P, Cohn J, D'Ascenzo M, Gordon JS, Rose JKC, Martin G, Tanksley SD, Bouzayen M, Jahn MM, Giovannoni J: ESTs, cDNA microarrays, and gene expression profiling: tools for dissecting plant physiology and development. Plant J 2004 39(5):697-714

40. Kang Y, Han YH, Torres-Jerez I, Wang MY, Tang YH, Monteros M, Udvardi M: System responses to long-term drought and re-watering of two contrasting alfalfa varieties. Plant J 2011, 68(5):871-889.

41. Nordborg M, Weigel D: Next-generation genetics in plants. Nature 2008 , 456(7223):720-723

42. Yoder JB, Briskine R, Mudge J, Farmer A, Paape T, Steele K, Weiblen GD, Bharti AK, Zhou P, May GD, Young ND, Tiffin P: Phylogenetic Signal Variation in the Genomes of Medicago (Fabaceae). Syst Biol 2013, 62(3):424-438

43. Kochian LV: Cellular mechanisms of aluminum toxicity and resistance in plants. Annu Rev Plant Phys 1995, 46:237-260.

44. Deyholos MK, Sieburth LE: Separable whorl-specific expression and negative regulation by enhancer elements within the AGAMOUS second intron. Plant Cell 2000, 12(10):1799-1810.

45. Gidekel $M$, Jimenez $B$, HerreraEstrella $L$ : The first intron of the Arabidopsis thaliana gene coding for elongation factor 1 beta contains an enhancerlike element. Gene 1996, 170(2):201-206.

46. Merchan F, de Lorenzo L, Rizzo SG, Niebel A, Manyani H, Frugier F, Sousa C, Crespi M: Identification of regulatory pathways involved in the reacquisition of root growth after salt stress in Medicago truncatula. Plant J 2007, 51(1):1-17.

47. Urao T, Yamaguchishinozaki K, Urao S, Shinozaki K: An Arabidopsis myb homolog is induced by dehydration stress and its gene-product binds to the conserved MYB recognition sequence. Plant Cell 1993, 5(11):1529-1539.
48. Nakashima K, Fujita Y, Katsura K, Maruyama K, Narusaka Y, Seki M, Shinozaki $K$, Yamaguchi-Shinozaki K: Transcriptional regulation of $A B \mid 3$-and ABAresponsive genes including $R D 29 B$ and $R D 29 A$ in seeds, germinating embryos, and seedlings of Arabidopsis. Plant Mol Biol 2006, 60(1):51-68.

49. Simpson SD, Nakashima K, Narusaka Y, Seki M, Shinozaki K, YamaguchiShinozaki K: Two different novel cis-acting elements of erd1, a clpA homologous Arabidopsis gene function in induction by dehydration stress and dark-induced senescence. Plant J 2003, 33(2):259-270.

50. Chinnusamy V, Ohta M, Kanrar S, Lee BH, Hong XH, Agarwal M, Zhu JK: ICE1: a regulator of cold-induced transcriptome and freezing tolerance in Arabidopsis. Gene Dev 2003, 17(8):1043-1054.

51. Chen WQ, Provart NJ, Glazebrook J, Katagiri F, Chang HS, Eulgem T, Mauch F, Luan S, Zou GZ, Whitham SA, Budworth PR, Tao Y, Xie ZY, Chen X, Lam S, Kreps JA, Harper JF, Si-Ammour A, Mauch-Mani B, Heinlein M, Kobayashi K, Hohn T, Dangl JL, Wang X, Zhu T: Expression profile matrix of Arabidopsis transcription factor genes suggests their putative functions in response to environmental stresses. Plant Cell 2002, 14(3):559-574

52. Curie C, Panaviene Z, Loulergue C, Dellaporta SL, Briat JF, Walker EL: Maize yellow stripe1 encodes a membrane protein directly involved in $\mathrm{Fe}(\mathrm{III})$ uptake. Nature 2001, 409(6818):346-349.

53. Vonwiren $\mathrm{N}$, Mori $\mathrm{S}$, Marschner $\mathrm{H}$, Romheld $\mathrm{V}$ : Iron inefficiency in maize mutant ys1 (Zea mays L. Cv Yellow-Stripe) is caused by a defect in uptake of iron phytosiderophores. Plant Physiol 1994, 106(1):71-77.

54. DiDonato RJ, Roberts LA, Sanderson T, Eisley RB, Walker EL: Arabidopsis Yellow Stripe-Like2 (YSL2): a metal-regulated gene encoding a plasma membrane transporter of nicotianamine-metal complexes. Plant J 2004, 39(3):403-414

55. Conte SS, Walker EL: Transporters contributing to iron trafficking in plants. Mol Plant 2011, 4(3):464-476

56. Wang Z, Shen J, Zhang F: Cluster-root formation, carboxylate exudation and proton release of Lupinus pilosus Murr. as affected by medium $\mathrm{pH}$ and P deficiency. Plant Soil 2006, 287(1-2):247-256.

57. Ewing B, Green P: Base-calling of automated sequencer traces using phred. II. Error probabilities. Genome Res 1998, 8(3):186-194.

58. Ewing B, Hillier L, Wendl MC, Green P: Base-calling of automated sequencer traces using phred. I. Accuracy assessment. Genome Res 1998 8(3):175-185.

59. Li R, Yu C, Li Y, Lam TW, Yiu SM, Kristiansen K, Wang J: SOAP2: an improved ultrafast tool for short read alignment. Bioinformatics 2009, 25(15):1966-1967.

60. Higo K, Ugawa $Y$, Iwamoto M, Korenaga T: Plant cis-acting regulatory DNA elements (PLACE) database: 1999. Nucleic Acids Res 1999, 27(1):297-300.

doi:10.1186/1471-2229-14-122

Cite this article as: Wang et al:: Genome variations account for different response to three mineral elements between Medicago truncatula ecotypes Jemalong A17 and R108. BMC Plant Biology 2014 14:122.

\section{Submit your next manuscript to BioMed Central and take full advantage of:}

- Convenient online submission

- Thorough peer review

- No space constraints or color figure charges

- Immediate publication on acceptance

- Inclusion in PubMed, CAS, Scopus and Google Scholar

- Research which is freely available for redistribution 